\title{
Characterization of a novel bioflocculant from a marine bacterium and its application in dye wastewater treatment
}

\author{
Zhen Chen ${ }^{1,2,3}$, Zhipeng Li ${ }^{1,2}$, Peize Liu ${ }^{1,2}$, Yu Liu ${ }^{1,2}$, Yuanpeng Wang ${ }^{1,2}$, Qingbiao Li ${ }^{1,2}$ and Ning He ${ }^{1,2^{*}}$
}

\begin{abstract}
Background: The identification of microorganisms with excellent flocculant-producing capability and optimization of the fermentation process are necessary for the wide-scale application of bioflocculants. Thus, we evaluated the flocculant-producing ability of a novel strain identified by the screening of marine bacteria, and we report for the first time the properties of the bioflocculant produced by Alteromonas sp. in the treatment of dye wastewater.

Results: A bioflocculant-producing bacterium was isolated from seawater and identified as Alteromonas sp. CGMCC 10612. The optimal carbon and nitrogen sources for the strain were $30 \mathrm{~g} / \mathrm{L}$ glucose and $1.5 \mathrm{~g} / \mathrm{L}$ wheat flour. In a $2-\mathrm{L}$ fermenter, the flocculating activity and bioflocculant yield reached maximum values of $2575.4 \mathrm{U} / \mathrm{mL}$ and $11.18 \mathrm{~g} / \mathrm{L}$, respectively. The bioflocculant was separated and showed good heat and pH stability. The purified bioflocculant was a proteoglycan consisting of $69.61 \%$ carbohydrate and $21.56 \%$ protein $(\mathrm{wt} / \mathrm{wt})$. Infrared spectrometry further indicated the presence of hydroxyl, carboxyl and amino groups preferred for flocculation. The bioflocculant was a nanoparticle polymer with an average mass of 394,000 Da. The purified bioflocculant was able to remove Congo Red, Direct Black and Methylene Blue at efficiencies of $98.5 \%, 97.9 \%$ and $72.3 \%$ respectively.
\end{abstract}

Conclusions: The results of this study indicated that the marine strain Alteromonas sp. is a good candidate for the production of a novel bioflocculant and suggested its potential industrial utility for biotechnological processes.

Keywords: Bioflocculant, Alteromonas sp., Marine bacterium, Dye wastewater

\section{Background}

Flocculation is considered an easy, low-cost and eco-friendly separation process [1] and is carried out in a variety of industrial processes, including wastewater refinement, processes in the food-related and fermentation industries, and drinking water purification [2,3]. Bioflocculants are natural macromolecular polymers produced by microorganisms that are capable of flocculating various suspended solids, such as cells and colloidal solids, with the character of harmless and biodegradable [4]. Therefore, bioflocculants have been extensively employed in removing pollutants (such as dye particles [5], heavy metal ions [6] and arsenite

\footnotetext{
* Correspondence: hening@xmu.edu.cn

'Department of Chemical and Biochemical Engineering, College of Chemistry and Chemical Engineering, Xiamen University, Xiamen 361005, People's Republic of China

${ }^{2}$ The Key Lab for Synthetic Biotechnology of Xiamen City, Xiamen University, Xiamen 361005, People's Republic of China

Full list of author information is available at the end of the article
}

[7]) from wastewater, for sludge thickening and dewatering $[8,9]$ and for the harvesting of microbial biomass [10]. Bioflocculant-producing microorganisms have been isolated from a wide variety of ecosystems such as wastewater, rivers, soil and activated sludge [11]. In general, biological flocculation is a dynamic process, which often occurs in the aerobic treatment of activated sludge. Thus, activated sludge is considered one of the best and most favoured sources of bioflocculant-producing strains. A variety of microorganisms including Chryseobacterium daeguense [12], Rhodococcus erythropolis [13] and Solibacillus silvestris [14] have been isolated from activated sludge. Recently, some microorganisms that produce bioflocculants have also been isolated from unusual environments such as sputum [15] and human saliva [16].

Although many bioflocculants have been idntified, their large-scale production is still limited by low yield, high production cost, and week activity [3]. Thus, the search for microorganisms with better bioflocculant-producing 
capacities and the optimization of medium constituents and fermentation conditions are still effective strategies to improve bioflocculant yields and flocculating activity. Recent efforts to reduce the production cost of bioflocculants have been effective but not sufficient. The utilization of inexpensive substrates for bioflocculant production has been investigated. Pseudomonas veronii can produce a bioflocculant from the hydrolyzate of peanut hull, which can effectively save the production cost of bioflocculant [17]. Other agricultural wastes, such as rice stover and corn stover, have also been applied as inexpensive carbon sources to produce bioflocculants $[18,19]$. Various wastewaters, including potato starch wastewater and chromotropic acid wastewater, have been used as cheap carbon sources to reduce the production cost $[9,20]$. Other reports focus on the optimization of the culture media and conditions for bioflocculant production [7, 21]. Marine habitats, that support a rich biodiversity of marine bacteria, remain underexplored for industrial utilization and yet possess enormous potentials for screening novel bioflocculant-producing microorganisms. Due to their species diversity, marine microorganisms can produce a wide variety of metabolites with various structures [22]. In recent years, research on the abilities of marine microbes to secrete bioflocculant is receiving increasing attention [23, 24].

In this study, a marine bacterium, Alteromonas sp. CGMCC 10612, with excellent bioflocculant-producing capability was isolated, and a novel proteoglycan bioflocculant was identified. Subsequently, the actual applications of this bioflocculant in the treatment of various dye wastewaters were investigated under a variety of conditions. According to our literature search, no previous report has documented the use of Alteromonas sp. in the production of bioflocculant.

\section{Methods}

Isolation and identification of Bioflocculant-producing strains Bioflocculant-producing strains were isolated from the surface seawater collected from the SEATS station in the South China Sea $\left(18^{\circ} \mathrm{N}, 116^{\circ} \mathrm{E}\right)$. The enrichment culture was set up with $2 \%(v / v)$ seawater in a medium containing $(\mathrm{g} / \mathrm{L})$ tryptone 10.0, yeast extract 5.0, nutrient broth 0.5 , sea salt 34.0 , sodium citrate 0.5 , sodium acetate 1.0 and $\mathrm{NH}_{4} \mathrm{NO}_{3} 0.2$ (pH 7.5). The enrichment test was performed under aerobic conditions on a rotary shaker at $30{ }^{\circ} \mathrm{C}$ and $150 \mathrm{rpm}$. After a 24-h incubation, $1 \mathrm{~mL}$ of culture broth was inoculated to the same medium three times to enrich the microbial culture.

The enrichment culture was diluted and spread onto agar plates containing the following sterilized medium $(\mathrm{g} / \mathrm{L})$ : glucose 10.0, urea 1.0, yeast extract 1.0, sea salt 34.0, $\mathrm{KH}_{2} \mathrm{PO}_{4} 0.1$ and $\mathrm{K}_{2} \mathrm{HPO}_{4} 0.1$ (pH 7.5). After cultivation for 2 days at $30{ }^{\circ} \mathrm{C}$, single colonies with mucoid and ropy morphology were picked and inoculated into liquid for $48 \mathrm{~h}$ at $30{ }^{\circ} \mathrm{C}$ and $150 \mathrm{rpm}$. The strains with the ability to produce bioflocculant were selected and spread onto agar plates for $48 \mathrm{~h}$ at $30{ }^{\circ} \mathrm{C}$, followed with 5 cycles of agar plate coating to ensure the purities of the strains with the highest flocculating activity.

The bioflocculant-producing strains were identified on the basis of the 16S rRNA gene according to the method in a previous study [17]. The genomic DNA from Alteromonas sp. CGMCC 10612 was extracted using an E.Z.N.A. Bacterial DNA Kit (OMEGA, Norcross, GA). The $16 \mathrm{~S}$ rRNA gene was sequenced by Sangon (China) and analysed by blast in the National Center for Biotechnology Information (NCBI) Database.

\section{Determination of flocculating activity}

Flocculating activity was determined using kaolin-clay suspensions as an indicator as described previously [25]. Each sample was analysed in triplicate. A control was performed with uninoculated culture medium substituted for the sample.

\section{Effects of initial $\mathrm{pH}$, temperature, sources of carbon and nitrogen and metal ions on the Bioflocculant production} Alteromonas sp. CGMCC 10612 was selected for further experimental investigation to optimize the process parameters. Except as otherwise noted, all liquid cultures were grown in triplicate in $250-\mathrm{mL}$ flasks containing $50 \mathrm{~mL}$ of medium on a rotary shaker at $30{ }^{\circ} \mathrm{C}$ and $150 \mathrm{rpm}$. To obtain the optimum fermentation temperature, the bacteria were cultured at $20,25,30,37$ and $42{ }^{\circ} \mathrm{C}$, and then the flocculating activity and $\mathrm{OD}_{600}$ of the 48 -h broth were determined. The effects of $\mathrm{pH}$ variation in the range of $4.0-10.0$ on the cell growth and bioflocculant production were also analysed. Bioflocculant production was also monitored using various carbon sources such as glucose, sucrose, starch, fructose, glycerol, lactose and sodium citrate at $10 \mathrm{~g} / \mathrm{L}$. The impact of various organic and inorganic nitrogen sources such as yeast extract, tryptone, beef extract, soy flour, wheat flour, urea, $\mathrm{NaNO}_{3}$ and $\mathrm{NH}_{4} \mathrm{Cl}$ was also explored when the medium contained glucose as the carbon source and the initial $\mathrm{pH}$ was 7.5. Furthermore, the effects of different proportions of phosphate as well as different concentrations of sea salt, glucose and wheat flour on the production of the bioflocculant from Alteromonas sp. CGMCC 10612 were investigated.

\section{Culture process in a 2-L fermenter}

Fermentation was carried out in a 2-L fermenter (ez-Control, made in Holland) containing $1.5 \mathrm{~L}$ of fermentation medium with an inoculum of $50 \mathrm{~mL}$. The culture was carried out at $37^{\circ} \mathrm{C}$, and DO was automatically controlled to remain no lower than $30 \%$. Samples were taken every $4 \mathrm{~h}$ and then subjected to further analysis. 


\section{Purification of the Bioflocculant}

The fermentation broth was centrifuged at 12,000 rpm for $10 \mathrm{~min}$ to remove bacteria. The supernatant was then mixed with 3 volumes of chilled ethanol and left to stand at $4{ }^{\circ} \mathrm{C}$ overnight. The resultant precipitate was collected by centrifugation at $8000 \mathrm{rpm}$ for $15 \mathrm{~min}$, and the crude bioflocculant was obtained. The crude bioflocculant was redissolved in distilled water, followed by dialysis using a membrane with a 7000-14,000 MWCO at $4{ }^{\circ} \mathrm{C}$ for $12 \mathrm{~h}$. Three volumes of cold ethanol were then added. After $2 \mathrm{~h}$, the resulting precipitate was collected by centrifugation at $8000 \mathrm{rpm}$ for $15 \mathrm{~min}$ and finally lyophilized to collect the purified bioflocculant.

\section{Characterization of purified bioflocculant Compositional analysis of purified bioflocculant}

The total protein content and sugar content of the purified bioflocculant were determined by the Lowry method using bovine serum albumin as the standard solution and the phenol-sulfuric acid method using glucose as the standard solution, respectively. The purified bioflocculant was hydrolyzed with trifluoroacetic acid at $121{ }^{\circ} \mathrm{C}$ for $2 \mathrm{~h}$ to obtain the component sugars. The resultant amino sugars, neutral sugars and uronic acid content were determined using the Elson-Morgan method, the anthrone reaction method and the carbazole-sulfuric acid method [26].

\section{Elementary analysis}

Carbon, hydrogen and nitrogen were analysed using an Elemental Analyzer (Vario EL III). For this purpose, $10 \mathrm{mg}$ of freeze-dried bioflocculant was placed in tin cups, and the mode of operation was selected as $\mathrm{CHN}$.

\section{FTIR spectroscopy of purified bioflocculant}

The functional groups of purified bioflocculant were determined using a Fourier transform infra-red (FT-IR) spectrophotometer (Thermo Electron Corporation, USA) over a wavenumber range of $4000-500 \mathrm{~cm}^{-1}$.

\section{Molecular weight determination of purified bioflocculant}

The molecular weight of the bioflocculant was determined by high-performance gel permeation chromatography (HPGPC) coupled to refractive index (RI) detection as described previously [25].

\section{Scanning electron microscopy (SEM) imaging}

The purified bioflocculant was re-dissolved in the purified water as the samples. The samples were placed on a silicon wafer and gold coated in a gold-coating chamber using an Eiko IB.3 ION coater. Scanning electron microscopy (SEM) images of the bioflocculant were obtained using an FEI XL30 (FEI; Netherlands).

\section{Stability analysis of purified bioflocculant}

To examine the thermal stability of the bioflocculant, the purified bioflocculant was incubated at $100{ }^{\circ} \mathrm{C}$ for different times $(15,30,45$ and $60 \mathrm{~min})$. To investigate the effect of $\mathrm{pH}$ on flocculating activity, the $\mathrm{pH}$ of the kaolin-clay suspensions were adjusted to the $\mathrm{pH}$ range of 3-11 using $\mathrm{HCl}$ or $\mathrm{NaOH}$.

\section{Coagulation-flocculation experiments}

First, $1.0 \mathrm{~mL}$ of bioflocculant was added to $99 \mathrm{~mL}$ of dye solution $(100 \mathrm{mg} / \mathrm{L})$. The coagulation procedure was as follows: rapid mixing (200 rpm) for $1.0 \mathrm{~min}$ followed by slow mixing (100 rpm) for $10 \mathrm{~min}$ and then a transfer into a $100-\mathrm{mL}$ measuring cylinder and sedimentation for $60 \mathrm{~min}$. After flocculation, the supernatants were collected at $1 \mathrm{~cm}$ below the wastewater surface and filtered through a slow Whatman filtration membrane, then analysed by a UV-visible spectrophotometer at the maximum adsorption wavelength. The colour removal efficiency was calculated as follows:

Dye removal efficiency $(\%)=\left(\mathrm{C}_{0}-\mathrm{Ce}\right) / \mathrm{C}_{0} \times 100 \%$. where $\mathrm{C}_{0}$ and $\mathrm{Ce}$ were the initial and final concentrations of the dye solution, respectively.

\section{Results and discussion}

Isolation of Bioflocculant-producing bacterium

Approximately 285 bacterial isolates were obtained from seawater samples, and 32 isolates were selected to be screened for bioflocculant production. After three subcultures, only 4 strains were able to actively flocculate kaolin suspension, as measured. Among them, the bacterium named $\mathrm{H}-6$ with the highest flocculating activity $(259.21 \mathrm{U} / \mathrm{mL})$ was selected as the bioflocculant-producing bacterium for further study and is currently preserved at the China General Microbiological Culture Collection Centre (registration number is CGMCC 10612). The flocculating efficiency of strain H-6 against kaolin suspension before medium optimization could be up to $96 \%$, which is much higher than that of recently reported strains such as Achromobacter xylosoxidans strain TERIL1 (83.3\%) [27] and Arthrobacter humicola strain R1 (85\%) [28].

\section{Identification and characterization of Bioflocculant- producing bacterium}

The colonies of strain CGMCC 10612 were round in shape with a neat edge and a central uplift. The surface was smooth and translucent with a greyish-yellow colour. Cells of strain CGMCC 10612 were gram-negative, non-spore forming, short rod shaped and small in size. The physiological and biochemical characteristics of strain CGMCC 10612 are summarized in Table 1 and were basically consistent with Alteromonas macleodii [29]. Compared to the 16S rDNA sequences deposited in the NCBI GenBank database, the $16 \mathrm{~S}$ rDNA Sequence of strain 
Table 1 Biophysiological and biochemical properties of strain

\begin{tabular}{lll}
$\mathrm{H}-6$ & Strain $\mathrm{H}-6$ & Alteromonas macleodii \\
\hline Test & + & + \\
\hline Starch hydrolysis & + & + \\
Catalase & + & + \\
$\mathrm{H}_{2}$ S production & + & + \\
Gelatin hydrolysis & - & 0 \\
Indole test & - & + \\
Methyl-red test & - & - \\
Voges-Proskauer test & - & 0 \\
Citrate utilization & + & 0 \\
Arginine utilization & - & 0 \\
Phenylalanine utilization & + & + \\
Glucose utilization & + & + \\
Lactose utilization & + & + \\
Sucrose utilization & $\mathrm{G}^{-}$ & $\mathrm{G}^{-}$ \\
Gram reaction & &
\end{tabular}

(+) Positive reaction, (-) Negative reaction, (0) No test

CGMCC 10612 is most similar to that of Alteromonas sp., sharing $99 \%$ similarity. A phylogenetic tree was constructed according to the neighbour-joining algorithm (see Additional file 1). Therefore, strain CGMCC 10612 was identified as Alteromonas sp. by both its morphological/ physiological and its phylogenetic characteristics. The Alteromonas genus is widely distributed in marine environments. Related research has suggested that Alteromonas strains can disproportionately alter the fate of carbon in the mesotrophic ocean and act functionally in ecosystem [30]. There have been many reports that Alteromonas strains can produce extracellular polysaccharides [31-33]. However, Alteromonas sp. has not been reported as a bioflocculantproducing strain in previous studies.

\section{Optimization of culture conditions for Bioflocculant production \\ Effect of temperature and initial medium $\mathrm{pH}$ on Bioflocculant production}

Temperature and $\mathrm{pH}$ play important roles in the bacterial growth rate and enzymatic activity and thus impact the production of bioflocculants [34]. The effects of temperature and variation of the initial $\mathrm{pH}$ in the range of $4-10$ on bioflocculant production by strain CGMCC 10612 were investigated (see Additional file 2). The optimal temperature for the bioflocculant production of strain CGMCC 10612 was found to be $25{ }^{\circ} \mathrm{C}$, at which point $\mathrm{OD}_{600}$ reached its highest value. The flocculation activity decreased sharply to approximately $200 \mathrm{U} / \mathrm{mL}$ at $30{ }^{\circ} \mathrm{C}$. The lower flocculation activity of strain CGMCC 10612 at high temperature could be attributed to decreased enzyme activity and biomass. In the initial $\mathrm{pH}$ range of $7-8$, considerable flocculating activity was observed, which indicated that production of this bioflocculant is appropriate to neutral and moderately alkaline conditions. The optimal initial $\mathrm{pH}$ was 7.5 , at which the flocculating activity reached $600 \mathrm{U} / \mathrm{mL}$.

\section{Effect of carbon and nitrogen sources on Bioflocculant production}

The importance of carbon and nitrogen sources for bioflocculant production has been emphasized [35, 36]. Carbon source plays a significant role in the growth of cells and the synthesis of varied metabolites during cultivation. Among the various carbon sources utilized, glucose exhibited the most prominent effect on the flocculating activity $(1515 \mathrm{U} / \mathrm{mL})$ followed by fructose $(1120 \mathrm{U} / \mathrm{mL})$. Starch and glycerol were conducive to the biomass accumulation of Alteromonas sp. but did not favour the production of bioflocculant. The carbon source requirements differ for different bacteria; for instance, glucose was preferred by Proteus mirabilis TJ-1 [37], while lactose was preferred by S. ficaria [38].

The effect of different nitrogen sources on the bioflocculant production of strain CGMCC 10612 was investigated by employing glucose as the carbon source and is illustrated in Fig. 1b. It was observed that the flocculating activity obtained with inorganic nitrogen sources was comparatively low. The addition of organic nitrogen sources, such as soy flour, wheat flour and yeast extract, is essential for optimum bioflocculant production. These results were consistent with the conclusion reported by Sekelwa et al. that organic nitrogen sources were more conducive to produce bioflocculant than inorganic nitrogen sources [39]. Strain CGMCC 10612 could grow well and produce considerable bioflocculant with high flocculating activities when yeast extract mixed with urea, soy flour and wheat flour was used as a nitrogen source. Considering the flocculating activity and economic factors, wheat flour was selected as the optimum nitrogen source.

\section{Effect of different proportions of phosphate on Bioflocculant production}

Phosphate can form a good buffer system, which plays an important role in the regulation of $\mathrm{pH}$ during fermentation. The properties of bioflocculant production by strain CGMCC 10612 were investigated. As shown in Fig. 2a, considerable bioflocculant could be produced by strain CGMCC 10612 when the proportion of phosphate ranged from 5:0 to 2:3. The biomass reached its highest value when the proportion of phosphate was 1:1. Considering the flocculating activity and microbial growth, a 1:1 proportion of phosphate was selected for further studies. 


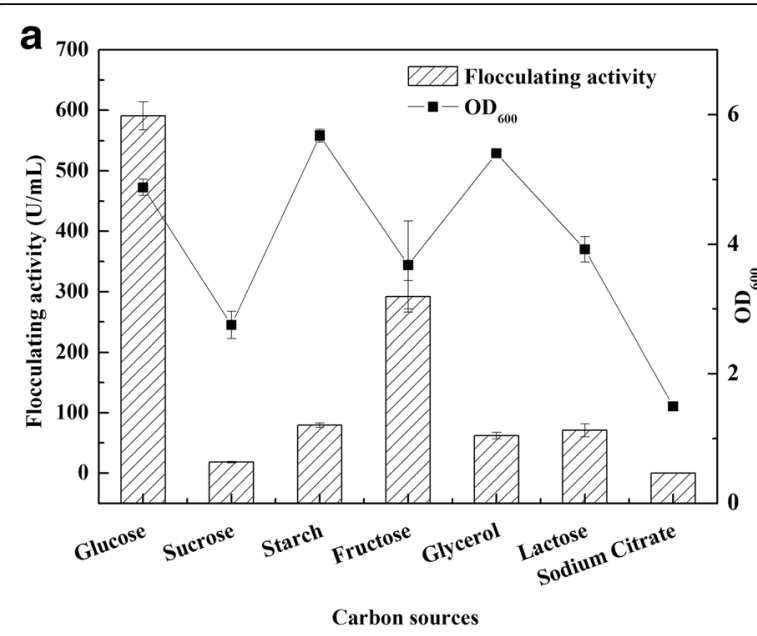

b

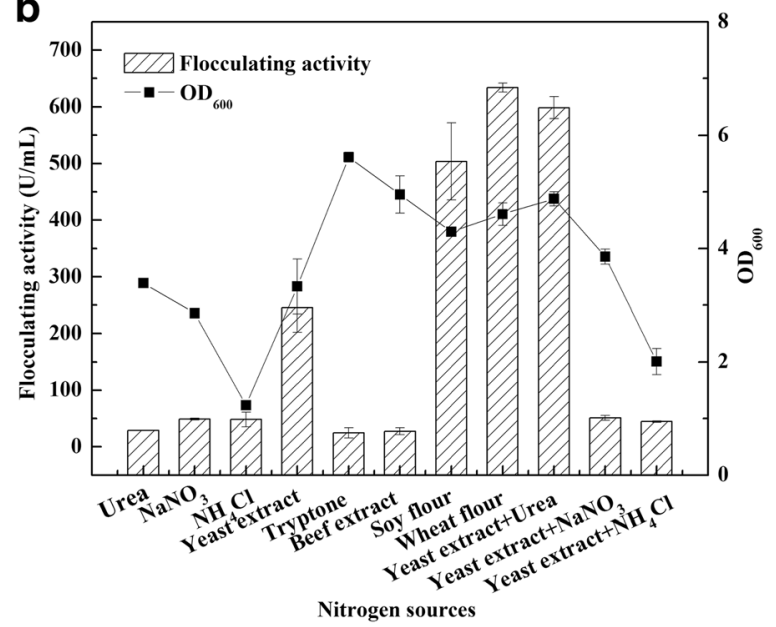

Fig. 1 Effects of different carbon sources (a) and nitrogen sources (b) on bioflocculant production

\section{Effect of different concentrations of sea salt on Bioflocculant production}

Sea salt not only provides the necessary salt-rich environment for marine bacteria to maintain osmotic pressure but also supplies the trace elements to promote microbial growth and bioflocculant production. Strain CGMCC 10612 was able to grow well in all salt concentration ranges tested, indicating that the strain possessed the property of adaptation to salinity variation (Fig. $2 \mathrm{~b}$ ). The highest flocculating activity was observed at the sea salt concentration of $30-40 \mathrm{~g} / \mathrm{L}$. Higher concentrations resulted in significant decreases in flocculating activity, which may be because microbial activity was inhibited by the hypersaline conditions.

\section{Effect of different concentrations of glucose on Bioflocculant production}

As a carbon source, glucose is an important factor for bacterial growth and the accumulation of secondary metabolites. As shown in Fig. 2c, the biomass and bioflocculant activity of strain CGMCC 10612 varied greatly at different concentrations of glucose. With increasing glucose concentration, the biomass increased to its highest value when the glucose concentration was $10 \mathrm{~g} / \mathrm{L}$, which was not sufficient to enhance the bioflocculant production. When the glucose concentration reached $30 \mathrm{~g} / \mathrm{L}$, the highest flocculating activity was obtained. Higher concentrations resulted in a significant decrease in flocculating activity, which may be due to the decline in biomass or to the accumulation of inactive by-products.

\section{Effect of different concentrations of wheat flour on Bioflocculant production}

The carbon/nitrogen source ratio can significantly influence the yield of bioflocculant because the $\mathrm{C} / \mathrm{N}$ ratio greatly affects microbial metabolism [34]. Therefore, the effect of the concentration of wheat flour on flocculating activity was determined when the carbon source was $30 \mathrm{~g} / \mathrm{L}$ glucose (Fig. 2d). The biomass increased gradually with increasing wheat flour concentration. The maximum bioflocculant production was achieved when the wheat flour concentration was $1.5 \mathrm{~g} / \mathrm{L}$. However, a further increase in wheat flour concentration caused a decline in bioflocculant production, indicating that the decline in the $\mathrm{C} / \mathrm{N}$ ratio was not conducive to bioflocculant production.

Scale-up of Bioflocculant production in a 2-L Fermenter After optimization of the fermentation conditions and medium, the ability of Alteromonas sp. CGMCC 10612 to produce bioflocculant during large-scale fermentation was investigated in a 2-L fermenter. A typical fermentation profile in terms of $\mathrm{DO}, \mathrm{pH}, \mathrm{OD}_{600}$ and flocculating activity is shown in Fig. 3. During the fermentation process, the agitation speed was kept at $150 \mathrm{rpm}$ and the temperature at $25{ }^{\circ} \mathrm{C}$, while the $\mathrm{pH}$ of the fermentation was not controlled but was monitored. The initial $\mathrm{pH}$ was approximately 6.8 to 7.0 , and the $\mathrm{pH}$ to 5.3 at the end of the fermentation. The decrease in $\mathrm{pH}$ is thought to be attributable to the oxidation of glucose to gluconic acid. After inoculation, the dissolved oxygen gradually decreased, and after $4 \mathrm{~h}, \mathrm{OD}_{600}$ appeared to undergo a sharp increase corresponding to rapid bacteria growth. It was observed that the flocculating activity increased progressively with increasing optical density of the culture, which signalled that the production of bioflocculant was positively associated with cell growth. The flocculating activity reached $2575.4 \mathrm{U} / \mathrm{mL}$ after $56 \mathrm{~h}$ of fermentation, which was $93.3 \%$ higher than the activity obtained during shake flask cultivation. The yield finally reached $11.18 \mathrm{~g} / \mathrm{L}$, which was $83.9 \%$ greater than the yield seen during shake flask cultivation.

In the shake flask, the bioflocculant production of most of the bioflocculant-produced strains, such as Aspergillus 


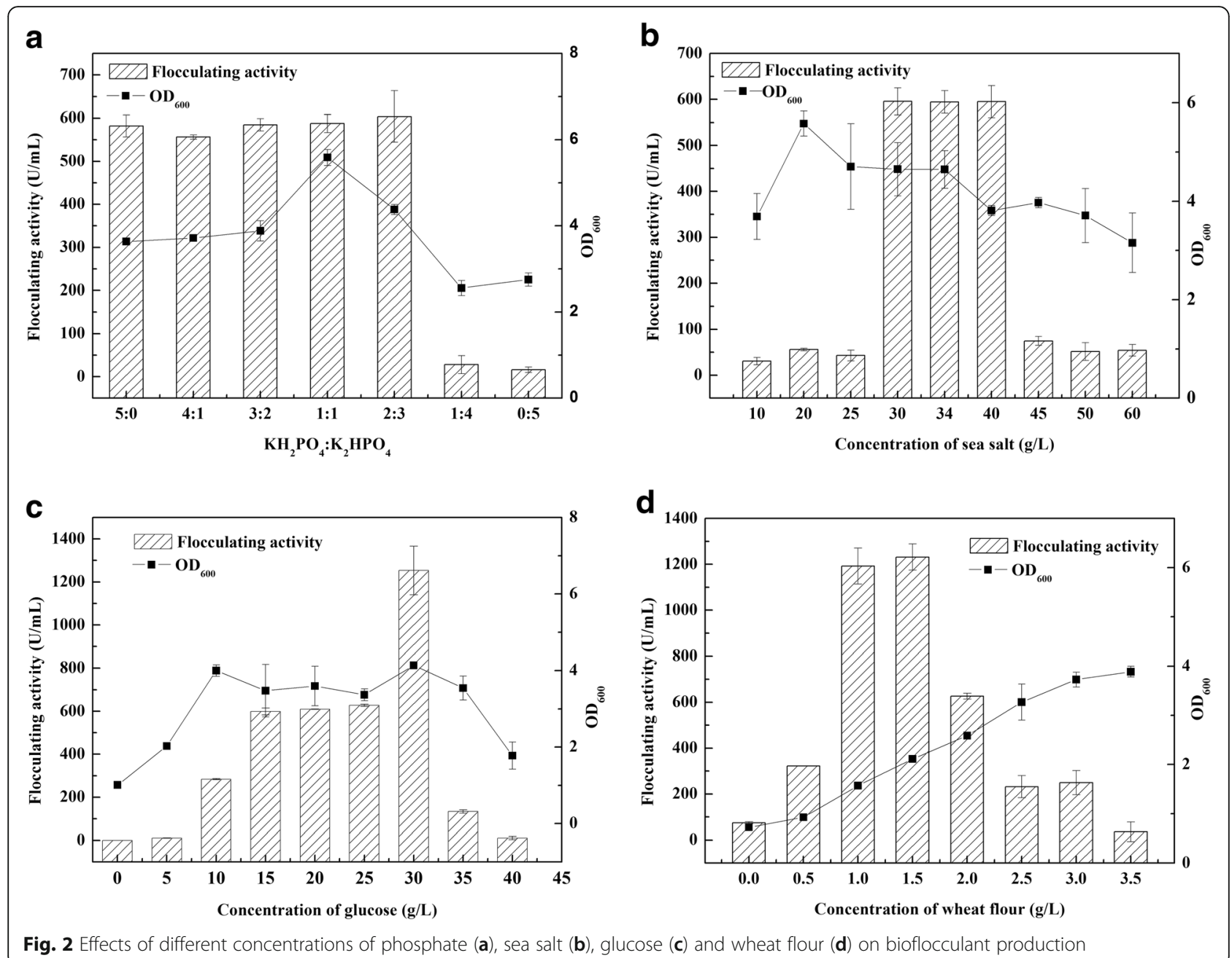

Fig. 2 Effects of different concentrations of phosphate (a), sea salt (b), glucose (c) and wheat flour (d) on bioflocculant production

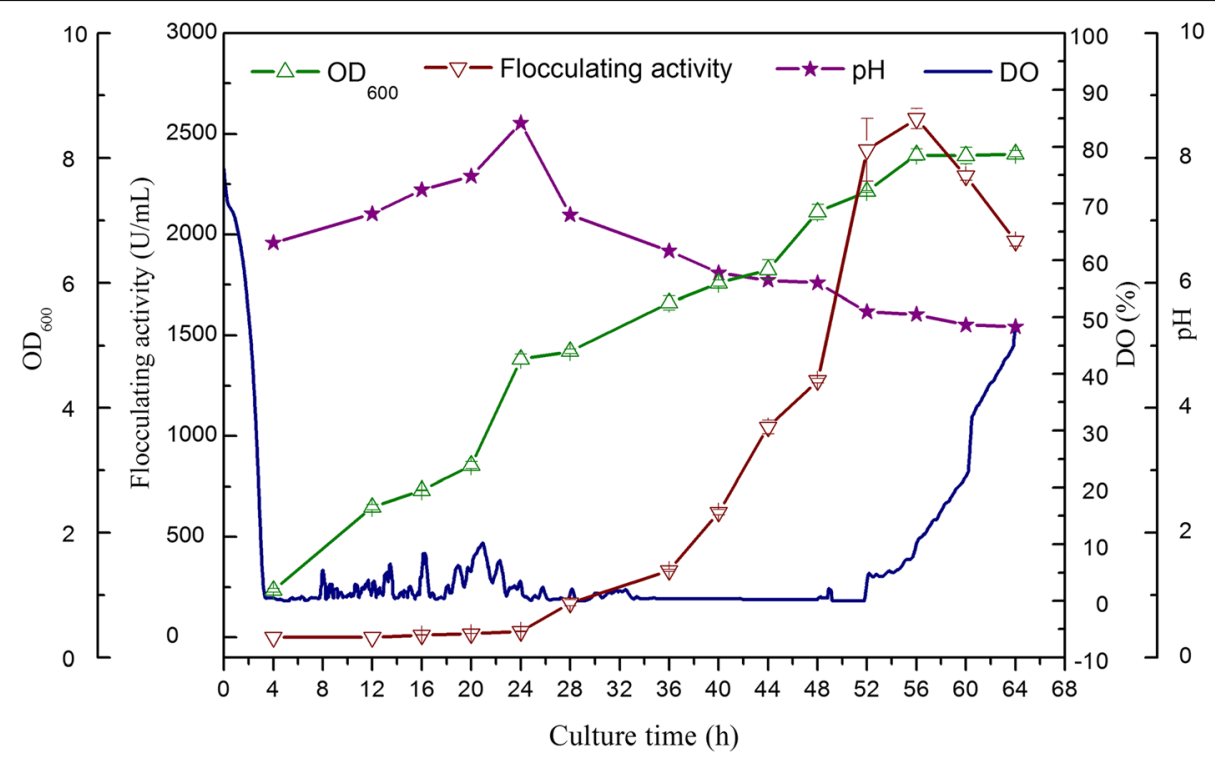

Fig. 3 Batch production of the bioflocculant in a 2-L fermenter by Alteromonas sp. CGMCC 10612 
flavus [40], Bacillus clausii [41] and Serratia ficaria [38], was lower than $3 \mathrm{~g} / \mathrm{L}$. In this study, it was reported to be $6.08 \mathrm{~g} / \mathrm{L}$, which was much higher than the yields described in previous studies. Although bioflocculant production has been investigated in prior studies, the yields have been relatively low. By scaling up fermentation from a flask to a 10-L fermenter, HBF-3 bioflocculant production was increased to $5.58 \mathrm{~g} / \mathrm{L}$ [42]. Patil S V et al. reported that the maximum EPS bioflocculant production was $6.10 \mathrm{~g} / \mathrm{L}$ in a 2.5-L fermenter using optimized medium [43]. This result demonstrates that Alteromonas sp. CGMCC 10612 has great potential in the industrial production of bioflocculant. The bioflocculant production of strain CGMCC 10612 during scale-up may be further improved by optimizing the feeding strategy.

\section{Characterization of Bioflocculant Composition analysis}

Elemental analysis showed that the bioflocculant from Alteromonas sp. CGMCC 10612 had a C content of $20.49 \%$, a $\mathrm{H}$ content of $4.48 \%$ and a $\mathrm{N}$ content of $5.54 \%$. The Folin-Lowry results revealed that the purified bioflocculant consisted of $21.56 \%$ proteins. The phenol-sulfuric acid analysis to determine the total sugar showed that the bioflocculant consisted of $69.61 \%$ sugars, indicating that polysaccharides were the major component of the bioflocculant. Further analysis indicated that the mass proportion of neutral sugar, uronic acid and amino sugar was 2:1:1. Sufficient content of uronic acid in a bioflocculant molecule can provide carboxyl groups to the molecular chain, which are preferred for the adsorption of particles and for flocculation [44]. It has been proven that flocculation capacity was positively associated with uronic acid content [45].

\section{Spectroscopic characterization}

The FTIR spectrum was determined and showed the presence of hydroxyl, amide and carboxyl groups in the bioflocculant (Fig. 4). The spectrum showed an intense and broad absorption peak at $3403 \mathrm{~cm}^{-1}$, which implied the presence of a hydroxyl or amide group. A weak $\mathrm{C}-\mathrm{H}$ stretching band was observed at $2856 \mathrm{~cm}^{-1}$ and is known to be typical of carbohydrates. A weak peak observed at $2358 \mathrm{~cm}^{-1}$ could be assigned to $\mathrm{CO}_{2}$ adsorption or to the amine group. An asymmetrical stretching peak at $1637 \mathrm{~cm}^{-1}$ could be attributed to the $\mathrm{C}=\mathrm{O}$ stretching vibration in $-\mathrm{NHCOCH}_{3}$. A strong absorption band at $1074 \mathrm{~cm}^{-1}$ indicated the asymmetrical stretching vibration of a $\mathrm{C}-\mathrm{O}-\mathrm{C}$ ester linkage. A strong band at $884.87 \mathrm{~cm}^{-1}$ could be associated with the $\beta$-glycosidic linkage between the sugar monomers. In addition, a weak peak at $611 \mathrm{~cm}^{-1}$ could be due to the stretching of $\mathrm{C}-\mathrm{Br}$ alkyl halides. The infrared spectrum showed characteristic peaks for carbohydrates and amides, which

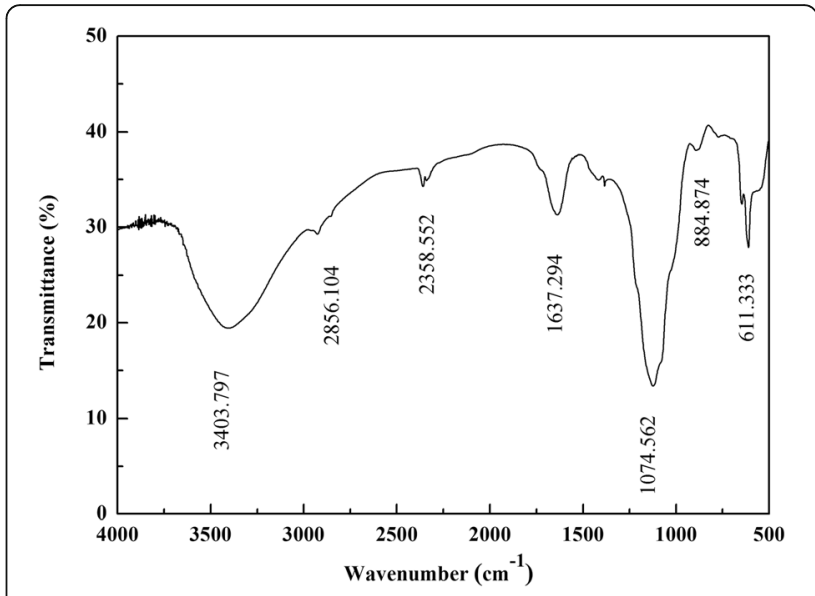

Fig. 4 Infrared spectra of the purified bioflocculant

serves as further confirmation that the bioflocculant produced by strain CGMCC 10612 most likely belongs to the glycoprotein group.

\section{Molecular weight and SEM analysis}

The HPGPC spectrum of the purified bioflocculant showed a symmetrical and sharp peak in the time of 20.556 min (Fig. 5a). The molecular mass-retention time equation accorded with the calibration curve was as follows: $\log$ (molecular weight $)=-0.1368 \mathrm{~T}+8.3496$. The average weight of the bioflocculant was calculated to be $3.94 \times 10^{5} \mathrm{Da}$, which is much higher than the weight of other bioflocculants reported previously [36, 40, 46]. Bioflocculants with high molecular weight present stronger bridging, more adsorption points, and higher flocculating activities than those with low molecular weight [4].

SEM observation was carried out to determine the surface morphology of the purified bioflocculant (Fig. 5b). Micrograph images of the purified bioflocculant revealed nano-structured granules with an average size of $200 \mathrm{~nm}$. The nanoparticle polymer was coarse-grained and varied in size. This property of the bioflocculant contributed not only to the flocculation of the kaolin-clay particles but also to sustained drug delivery, cancer chemotherapy and bioimaging [47].

\section{Stability analysis of Bioflocculant}

Investigation of the stability of the bioflocculant showed that the bioflocculant was relatively stable after a long period of heat treatment and at a wide range of $\mathrm{pH}$ values (Table 2). After heat treatment at $100{ }^{\circ} \mathrm{C}$ for $15 \mathrm{~min}$, the bioflocculant exhibited good flocculating capability without loss of activity, which could satisfy the requirements for practical use in industry. Meanwhile, over $82 \%$ of the flocculating activity was maintained after heat treatment at $100{ }^{\circ} \mathrm{C}$ for $30 \mathrm{~min}$. The bioflocculant was much more thermally stable than the recently 

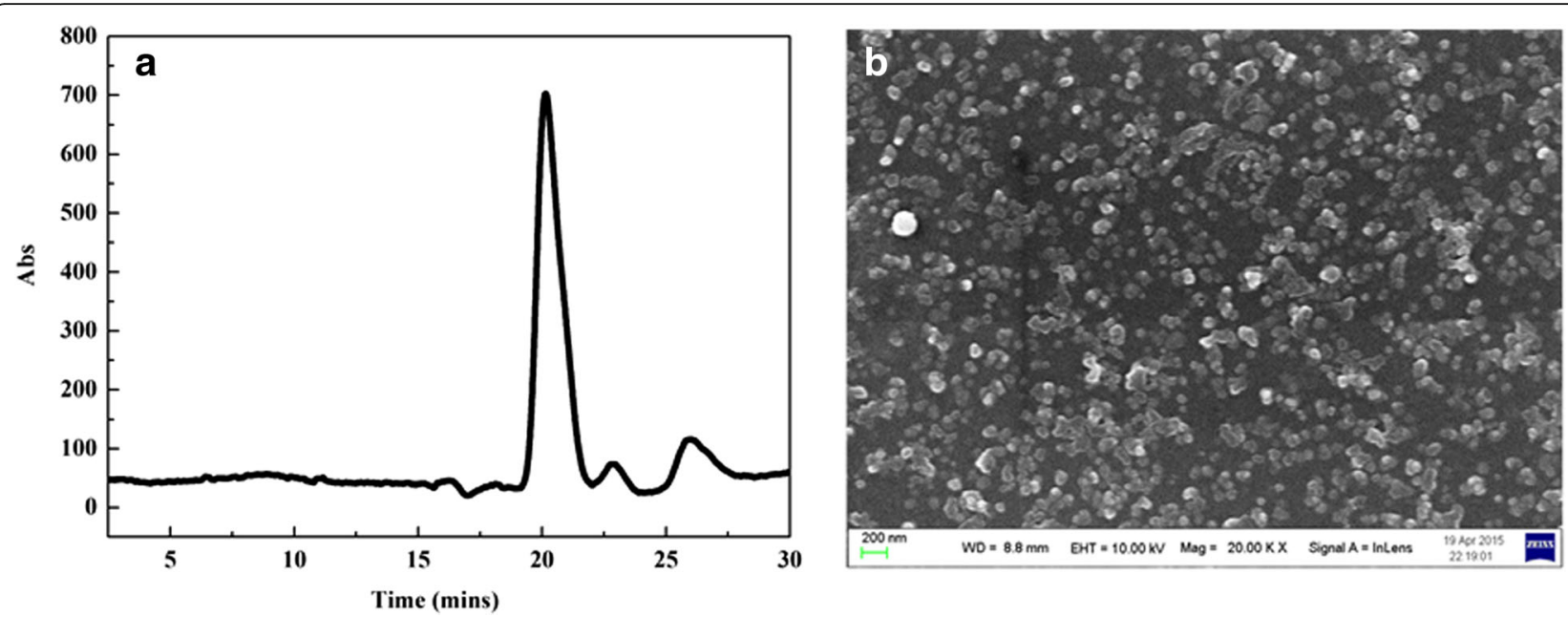

Fig. 5 Gel permeation chromatogram (a) and SEM (b) of the purified bioflocculant

reported polysaccharide bioflocculant, which decreased in activity by $65.2 \%$ after being heated at $80{ }^{\circ} \mathrm{C}$ for $30 \mathrm{~min}$ [48]. After heating at $100{ }^{\circ} \mathrm{C}$ for $60 \mathrm{~min}$, the bioflocculant activity still reached $850 \mathrm{U} / \mathrm{mL}$ with a $34.6 \%$ decrease, indicating that the protein is one of the functional components. The optimum $\mathrm{pH}$ for different bioflocculants may vary due to their different compositions. The electric states of the bioflocculant vary for different $\mathrm{pH}$, which in turn affect the flocculation ability of the bioflocculant for the kaolin particles. The highest flocculating activity of $1301.8 \mathrm{U} / \mathrm{mL}$ was attained at $\mathrm{pH}$ 9.0. The high flocculating activity achieved in a wide $\mathrm{pH}$ range suggests that this bioflocculant could be applied to treat various wastewaters in various industries without adjusting the $\mathrm{pH}$, thus rendering the bioflocculant cost-effective. Similar findings were reported for the bioflocculant produced by Bacillus pumilus, which presented good flocculation ability under both acidic and alkaline conditions [49].

\section{Decolorization by the Bioflocculant \\ Effect of solution $\mathrm{pH}$ on dye removal}

In the flocculation experiments, two anionic dyes (Congo Red and Direct Black) and one cationic dye (Methylene

Table 2 Effects of heating time and $\mathrm{pH}$ on the flocculating activity of the purified bioflocculant $(n=3$, mean \pm SD)

\begin{tabular}{llll}
\hline Heating time $(\mathrm{min})$ & $\mathrm{FA} \pm \mathrm{SD}(\mathrm{U} / \mathrm{mL})$ & $\mathrm{pH}$ & $\mathrm{FA} \pm \mathrm{SD}(\mathrm{U} / \mathrm{mL})$ \\
\hline 0 & $1313.1 \pm 5.8$ & 3 & $938.9 \pm 27.8$ \\
15 & $1289.2 \pm 16.0$ & 5 & $1119.4 \pm 25.6$ \\
30 & $1080.2 \pm 35.5$ & 7 & $1251.4 \pm 36.5$ \\
45 & $926.1 \pm 16.6$ & 9 & $1301.8 \pm 14.7$ \\
60 & $858.7 \pm 19.4$ & 11 & $1014.3 \pm 35.6$ \\
& & 13 & $695.9 \pm 69.4$ \\
\hline
\end{tabular}

Blue) were used with different $\mathrm{pH}$ values. The results showed that the bioflocculant exhibited different decolourization capacity depending on the dye used and the solution pH (Fig. 6a). For anionic dye, a gradual increase in decoloration efficiency was observed from $\mathrm{pH} 3.0$ to 11.0. The removal of anionic dyes was directly impacted by the availability and strength of positive charges in the solution, which in turn were fixed by the conformation and the cationicity of the bioflocculant. It can be explained by the theory reported by Somasundaran that $\mathrm{pH}$ influences the electrochemistry of the dyes and the dissociation of the polyelectrolytes, and hence their conformation in solution [50]. For cationic dye, the impact of $\mathrm{pH}$ on dye removal is not obvious, probably because of the cationic property of the bioflocculant. Overall, the bioflocculant had moderate removal ability for anionic dye, with the highest decolourization rates for Congo Red and Direct Black being $98.5 \%$ and $97.9 \%$, respectively; a lower rate was observed when used with cationic dyes for Methylene Blue, at $72.7 \%$. These results suggested that the bioflocculant was more effective for anionic dyes than cationic dyes. Similarly, the bioflocculant produced by Kocuria rosea was effective for the removal of anionic dyes [51]. In addition, the effect of mixing time on dye removal was investigated. The results showed that the dye removal efficiency after mixing the bioflocculant and dye for $5 \mathrm{~min}$ was identical to that after mixing for $10 \mathrm{~min}$, which indicated that the adsorption of dye by the bioflocculant is a very rapid process.

\section{Effect of Bioflocculant dosage on dye removal}

The dye removal efficiency of bioflocculant at different adsorbent doses $(20-220 \mathrm{mg} / \mathrm{L})$ is shown in Fig. 6b, and a comparison of dye wastewater before and after flocculation is presented in Fig. 6c. Generally, the removal 


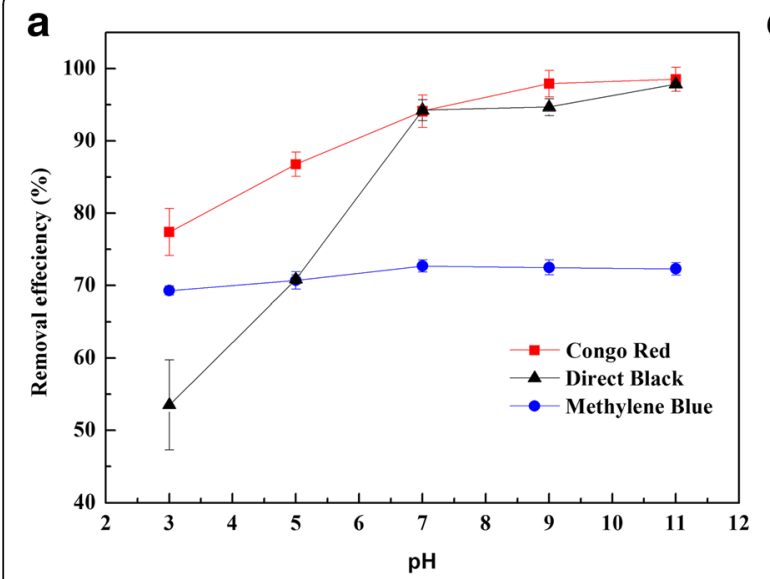

C
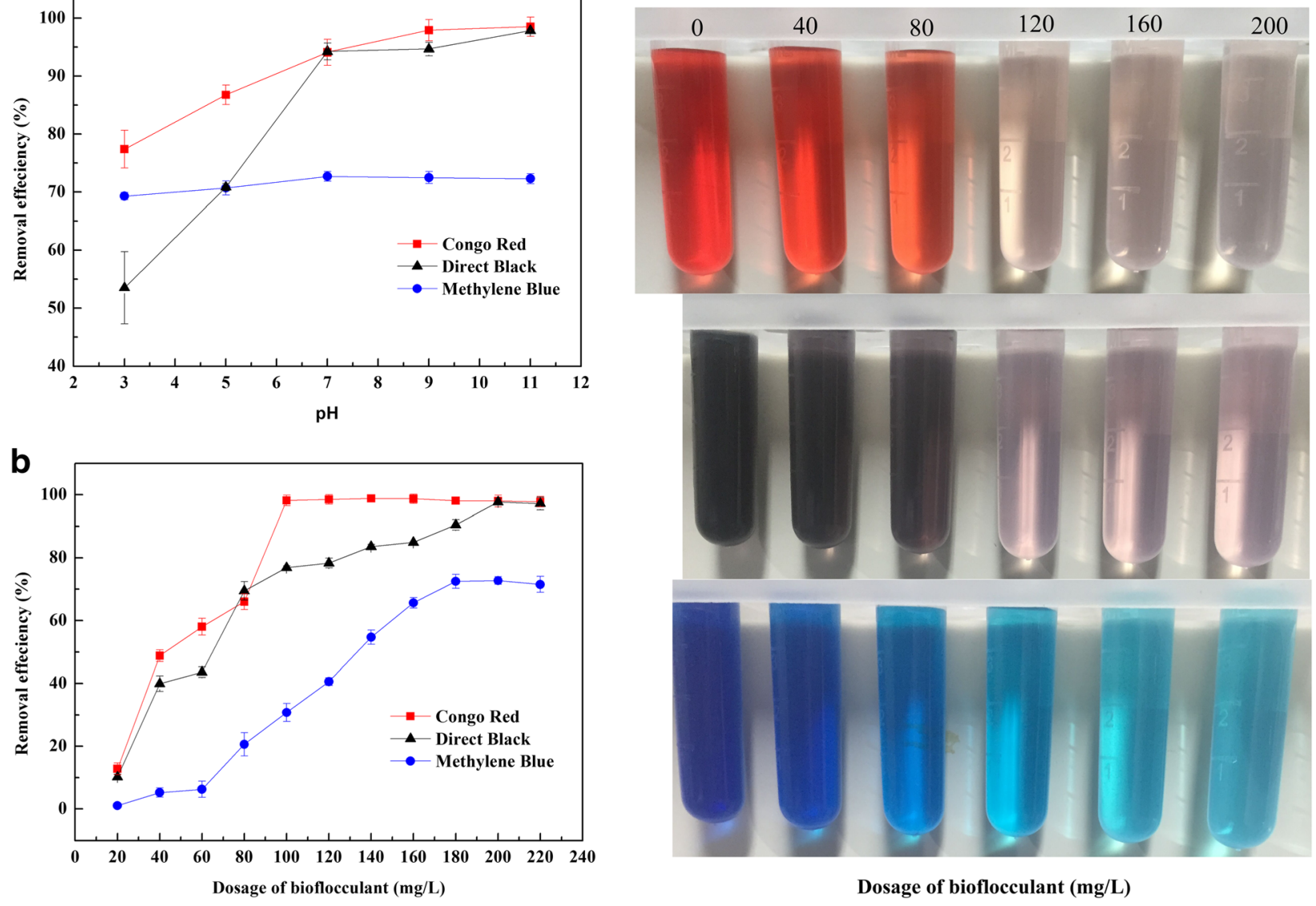

Fig. 6 Effects of solution $\mathrm{pH}$ (a) and bioflocculant dosage (b) on dye removal efficiency

efficiency increased with the bioflocculant dosage, which is due to the increase in absorbent surface area and adsorbing sites. When the bioflocculant was administered, microflocs aggregated into larger ones due to the adsorption/bridging ability of the polysaccharides. The optimal bioflocculant dosages for Congo Red, Direct Black and Methylene Blue were 100, 200 and $180 \mathrm{mg} / \mathrm{L}$, respectively. Further increasing the adsorbent resulted in a slight decrease in decolourization efficiency, since higher bioflocculant doses would inhibit small flocs from growing due to the stronger repulsion force between them [52]. Moreover, especially for anionic dyes, the bioflocculant exhibited excellent decolourization ability without the addition of any cationic salt.

\section{Conclusion}

A bioflocculant-producing strain was isolated from seawater and identified as Alteromonas sp. CGMCC 10612. A maximum bioflocculant production of $11.18 \mathrm{~g} / \mathrm{L}$ with a flocculating activity of $2575.4 \mathrm{U} / \mathrm{mL}$ was achieved in a 2-L fermenter. Its composition was predominantly polysaccharide (69.6\%), which explains its thermal stability. Further, its high content of uronic acid (14.5\%) indicated the presence of many functional groups containing nitrogen and oxygen atoms, which are preferred for flocculation. In addition, its high molecular weight $\left(3.94 \times 10^{5} \mathrm{Da}\right)$ strengthens its competitive advantage in bridging function and flocculation ability. Above all, its excellent decolourization ability suggests its potential industrial utility for biotechnological processes.

\section{Additional files}

Additional file 1: The phylogenetic tree of bioflocculant-producing strain H-6. (TIFF $52 \mathrm{~kb}$ )

Additional file 2: Effects of temperature (a) and initial $\mathrm{pH}$ (b) on bioflocculant production. (TIFF $1522 \mathrm{~kb}$ )

\section{Abbreviations}

DO: Dissolved oxygen; EPS: Exopolysaccharide; FA: Flocculating activity; FTIR: Fourier Transform Infra-Red; HPGPC: High-performance gel permeation chromatography; NCBI: National center for biotechnological information; OD: Optical density; SEM: Scanning electron microscopy

\section{Acknowledgements}

We gratefully acknowledge the editorial service American Journal Experts for their language polishing work. 


\section{Funding}

This work was financially supported by the National Natural Science Foundation of China $(51,378,444,21,676,221)$, the University of Science and Technology in Fujian Province in the cooperative major project (2015H6004), Xiamen Southern Oceanographic Center (15GYY024NF03) and Guangxi special funds project for Bagui scholars.

\section{Availability of data and materials}

The datasets used and analysed during the current study available from the corresponding author on reasonable request.

\section{Authors' contributions}

ZC, NH, YPW and QBL designed the experiments. PZL was responsible for data acquisition and fermentation assays. $Z C$ and $Y L$ preformed the other experiments. ZC, ZPL and $\mathrm{NH}$ analyzed the results. ZC, PZL, and $\mathrm{NH}$ wrote the manuscript which was reviewed and approved by all authors. All authors read and approved the final submission of the manuscript.

\section{Ethics approval and consent to participate}

Not applicable.

\section{Consent for publication}

Not applicable.

\section{Competing interests}

The authors declare that they have no competing interests.

\section{Publisher's Note}

Springer Nature remains neutral with regard to jurisdictional claims in published maps and institutional affiliations.

\section{Author details}

'Department of Chemical and Biochemical Engineering, College of Chemistry and Chemical Engineering, Xiamen University, Xiamen 361005, People's Republic of China. ${ }^{2}$ The Key Lab for Synthetic Biotechnology of Xiamen City, Xiamen University, Xiamen 361005, People's Republic of China. ${ }^{3}$ College of Life Sciences, Xinyang Normal University, Xinyang, Henan 464000, China.

\section{Received: 1 August 2017 Accepted: 31 October 2017}

\section{Published online: 17 November 2017}

\section{References}

1. Rossini M, Garrido JG, Galluzzo M. Optimization of the coagulationflocculation treatment: influence of rapid mix parameters. Water Res. 1999; 33(8):1817-26

2. Wang L, Ma F, Lee DJ, Wang A, Ren N. Bioflocculants from hydrolysates of corn stover using isolated strain Ochrobactium ciceri W2. Bioresour Technol. 2013:145(19):259-63.

3. Aljuboori AHR, Uemura Y, Osman NB, Yusup S. Production of a bioflocculant from Aspergillus niger using palm oil mill effluent as carbon source. Bioresour Technol. 2014;171(171):66-70

4. Salehizadeh H, Shojaosadati SA. Extracellular biopolymeric flocculants. Recent trends and biotechnological importance. Biotechnol Adv. 2001;19(5):371.

5. Chouchane H, Mahjoubi M, Ettoumi B, Neifar M, Cherif A. A novel thermally stable heteropolysaccharide-based bioflocculant from hydrocarbonoclastic strain Kocuria rosea BU22S and its application in dye removal. Environ Technol. 2017:1

6. Sajayan A, Seghal KG, Priyadharshini S, Poulose N, Selvin J. Revealing the ability of a novel polysaccharide bioflocculant in bioremediation of heavy metals sensed in a Vibrio bioluminescence reporter assay. Environ Pollut. 2017;228:118

7. Guo J, Chen C. Removal of arsenite by a microbial bioflocculant produced from swine wastewater. Chemosphere. 2017:181:759.

8. Busi S, Karuganti S, Rajkumari J, Paramanandham P, Pattnaik S. Sludge settling and algal flocculating activity of extracellular polymeric substance (EPS) derived from bacillus cereus SK. Water \& Environment Journal. 2017; 31(1):97-104.

9. Zhong C, Xu A, Li C, Yang X, Yang B, Hong W, Mao K, Wang B, Zhou J. Production of a bioflocculant from chromotropic acid waste water and its application in steroid estrogen removal. Colloids \& Surfaces B Biointerfaces. 2014;122:729-37.
10. Cong $L$, Yan $H$, Jiang J, Liu W. Valorization of untreated rice bran towards bioflocculant using a lignocellulose-degrading strain and its use in microalgal biomass harvest. Biotechnology for Biofuels. 2017;10(1):90.

11. Salehizadeh $H$, Vossoughi M, Alemzadeh I. Some investigations on bioflocculant producing bacteria. Biochem Eng J. 2000;5(1):39-44.

12. Liu WJ, Yuan HL, Yang JS, Li BZ. Characterization of bioflocculants from biologically aerated filter backwashed sludge and its application in dying wastewater treatment. Bioresour Technol. 2009;100(9):2629.

13. Peng L, Yang C, Zeng G, Lu W, Dai C, Long Z, Liu H, Zhong Y. Characterization and application of bioflocculant prepared by Rhodococcus erythropolis using sludge and livestock wastewater as cheap culture media. Applied Microbiology \& Biotechnology. 2014;98(15):6847-58.

14. Wan C, Zhao XQ, Guo SL, Asraful AM, Bai FW. Bioflocculant production from Solibacillus silvestris W01 and its application in cost-effective harvest of marine microalga Nannochloropsis oceanica by flocculation. Bioresour Technol. 2013;135(3):207-12.

15. Zhao HJ, Liu HT, Zhou JG. Characterization of a bioflocculant MBF-5 by Klebsiella pneumoniae and its application in Acanthamoeba cysts removal. Bioresour Technol. 2013;137:226-32.

16. Luo Z, Chen L, Chen C, Zhang W, Liu M, Han Y, Zhou J. Production and characteristics of a Bioflocculant by Klebsiella pneumoniae YZ-6 isolated from human saliva. Applied Biochemistry \& Biotechnology. 2014;172(3):1282-92.

17. Liu W, Hao Y, Jiang J, Zhu A, Zhu J, Dong Z. Production of a bioflocculant from Pseudomonas veronii L918 using the hydrolyzate of peanut hull and its application in the treatment of ash-flushing wastewater generated from coal fired power plant. Bioresour Technol. 2016;218:318-25.

18. Guo J, Du J, Chen P, Tan X, Huang X, Gan P, Fu L. Enhanced efficiencies of sludge dewatering and domestic wastewater treatment by using the bioflocculant from rice stover. Water \& Environment Journal. 2017;31(1):120-6.

19. Liu W, Zhao C, Jiang J, Lu Q, Hao Y, Wang L, Liu C. Bioflocculant production from untreated corn stover using Cellulosimicrobium cellulans L804 isolate and its application to harvesting microalgae. Biotechnology for Biofuels. 2015;8(1):1-12. 8,1(2015-10-20)

20. Guo J, Zhang Y, Zhao J, Zhang Y, Xiao X, Wang B, Shu B. Characterization of a bioflocculant from potato starch wastewater and its application in sludge dewatering. Appl Microbiol Biotechnol. 2015;99(13):5429-37.

21. Rasulov BA, Li L, Liu YH, Mohamad OA, Xiao M, Ma JB, Li WJ. Production, characterization and structural modification of exopolysaccharide-based bioflocculant by Rhizobium radiobacter SZ4S7S14 and media optimization. Biotech. 2017;7(3):179.

22. Finore I, Di DP, Mastascusa V, Nicolaus B, Poli A. Fermentation technologies for the optimization of marine microbial exopolysaccharide production. Marine Drugs. 2014;12(5):3005

23. Liu H, Chen G, Wang G. Characteristics for production of hydrogen and bioflocculant by Bacillus sp. XF-56 from marine intertidal sludge. Int J Hydrog Energy. 2015;40(3):1414-9.

24. Okaiyeto K, Nwodo UU, Mabinya LV, Okoli AS, Okoh Al. Evaluation of flocculating performance of a thermostable bioflocculant produced by marine Bacillus sp. Environ Technol. 2016;37(14):1829.

25. Xiong Y, Wang Y, Yu Y, Li Q, Wang H, Chen R, He N. Production and characterization of a novel Bioflocculant from Bacillus licheniformis. Applied \& Environmental Microbiology. 2010;76(9):2778-82.

26. Guo X, Gao XD, Yang XB. Determination of content glucuronic acid and neutral sugar of acidic polysaccharide. Chinese Journal of Biochemical Pharmaceutics. 2004;25(2):100-1.

27. Subudhi S, Bisht V, Batta N, Pathak M, Devi A, Lal B. Purification and characterization of exopolysaccharide bioflocculant produced by heavy metal resistant Achromobacter xylosoxidans. Carbohydr Polym. 2016;137:441.

28. Agunbiade $\mathrm{MO}$, Heerden EV, Pohl CH, Ashafa AT. Flocculating performance of a bioflocculant produced by Arthrobacter humicola in sewage waste water treatment. BMC Biotechnol. 2017;17(1):51.

29. Han B, Dai J, Wang H. Isolation and identification of alginate-degrading bacteria and formation of alginase. Acta Oceanol Sin. 1999;4:555-61.

30. Pedler BE, Aluwihare LI, Azam F. From the cover: single bacterial strain capable of significant contribution to carbon cycling in the surface ocean Proc Natl Acad Sci U S A. 2014;111(20):7202-7.

31. Costaouëc TL, Cérantola S, Ropartz D, Ratiskol J, Sinquin C, Colliec-Jouault S, Boisset C. Structural data on a bacterial exopolysaccharide produced by a deep-sea Alteromonas macleodii strain. Carbohydr Polym. 2012;90(1):49-59.

32. Mehta A, Sidhu C, Pinnaka AK, Roy CA. Extracellular polysaccharide production by a novel Osmotolerant marine strain of Alteromonas macleodii 
and its application towards biomineralization of silver. PLoS One. 2014;9(6): e98798.

33. Zhang Z, Li Z, Jiao N. Effects of $d$-amino acids on the EPS production and cell aggregation of Alteromonas macleodii strain JL2069. Curr Microbiol. 2014;68(6):751-5.

34. More TT, Yadav JS, Yan S, Tyagi RD, Surampalli RY. Extracellular polymeric substances of bacteria and their potential environmental applications. J Environ Manag. 2014;144(144):1-25.

35. Salehizadeh $\mathrm{H}$, Yan N. Recent advances in extracellular biopolymer flocculants. Biotechnol Adv. 2014;32(8):1506-22.

36. Li Z, Zhong S, Lei HY, Chen RW, Yu Q, Li HL. Production of a novel bioflocculant by Bacillus licheniformis X14 and its application to low temperature drinking water treatment. Bioresour Technol. 2009;100(14):3650-6.

37. Xia S, Zhang Z, Wang X, Yang A, Chen L. Jf, Leonard D, Jaffrezic-Renault N: production and characterization of a bioflocculant by Proteus mirabilis TJ-1. Bioresour Technol. 2008;99(14):6520-7.

38. Gong WX, Wang SG, Sun XF, Liu XW, Yue QY, Gao BY. Bioflocculant production by culture of Serratia ficaria and its application in wastewater treatment. Bioresour Technol. 2008:99(11):4668-74.

39. Sekelwa C, Anthony UM, Vuyani ML, Anthony Ol. Characterization of a thermostable polysaccharide bioflocculant produced by Virgibacillus specie isolated from Algoa Bay. Afr J Microbiol Res. 2013;7(23):2925-38.

40. Aljuboori AH, Idris A, Abdullah N, Mohamad R. Production and characterization of a bioflocculant produced by Aspergillus flavus. Bioresour Technol. 2013;127(1):489-93.

41. Adebayotayo B, Adebami GE. Production and characterization of bioflocculant produced by Bacillus clausii NB2. Innovative Romanian Food Biotechnology. 2014;14:13-25.

42. He J, Zhen Q, Qiu N, Liu Z, Wang B, Shao Z, Yu Z. Medium optimization for the production of a novel bioflocculant from Halomonas sp. V3a' using response surface methodology. Bioresour Technol. 2009;100(23):5922-7.

43. Patil SV, Salunkhe RB, Patil CD, Patil DM, Salunke BK Bioflocculant exopolysaccharide production by Azotobacter Indicus using flower extract of Madhuca Latifolia L. Applied Biochemistry \& Biotechnology. 2010;162(4):1095-108.

44. De PR, Colica G, Micheletti E. Exopolysaccharide-producing cyanobacteria in heavy metal removal from water: molecular basis and practical applicability of the biosorption process. Appl Microbiol Biotechnol. 2011;92(4):697-708

45. Tiwari ON, Khangembam R, Shamjetshabam M, Sharma AS, Oinam G, Brand JJ. Characterization and optimization of Bioflocculant exopolysaccharide production by Cyanobacteria Nostoc sp. BTA97 and anabaena sp. BTA990 in culture conditions. Applied Biochemistry \& Biotechnology. 2015;176(7):1950-63.

46. Li Q, Liu HL, Qi QS, Wang FS, Zhang YZ. Isolation and characterization of temperature and alkaline stable bioflocculant from Agrobacterium sp. M-503. New Biotechnol. 2010;27(6):789-94.

47. Raveendran S, Poulose AC, Yoshida Y, Maekawa T, Kumar DS. Bacterial exopolysaccharide based nanoparticles for sustained drug delivery, cancer chemotherapy and bioimaging. Carbohydr Polym. 2013;91(1):22-32.

48. Guo J, Yu J, Xin X, Zou C, Cheng Q, Yang H, Nengzi L. Characterization and flocculation mechanism of a bioflocculant from hydrolyzate of rice stover. Bioresour Technol. 2015;177(2):393.

49. Makapela B, Okaiyeto K, Ntozonke N, Nwodo U, Green E, Mabinya L, Okoh A. Assessment of Bacillus pumilus isolated from fresh water milieu for Bioflocculant production. Appl Sci. 2016;6(8):211.

50. Somasundaran P, Runkana V. Investigation of the flocculation of colloidal suspensions by controlling adsorbed layer microstructure and population balance Modelling. Chemical Engineering Research \& Design. 2005;83(7): 905-9147.

51. Chouchane H, Mahjoubi M, Ettoumi B, Neifar M, Cherif A. A novel thermally stable heteropolysaccharide based bioflocculant from hydrocarbonoclastic strain Kocuria rosea BU22S and its application in dye removal. Environ Technol. 2017:1:1-14.

52. Wu C, Wang Y, Gao B, Zhao Y, Yue Q. Coagulation performance and floc characteristics of aluminum sulfate using sodium alginate as coagulant aid for synthetic dying wastewater treatment. Separation \& Purification Technology. 2012;95(95):180-7.

\section{Submit your next manuscript to BioMed Central and we will help you at every step:}

- We accept pre-submission inquiries

- Our selector tool helps you to find the most relevant journal

- We provide round the clock customer support

- Convenient online submission

- Thorough peer review

- Inclusion in PubMed and all major indexing services

- Maximum visibility for your research

Submit your manuscript at www.biomedcentral.com/submit
Biomed Central 